\title{
Ultrasound Assessment of Pedal Soft Tissue Thickness in Diabetic Patients With and Without Peripheral Neuropathy
}

\author{
NEHAL T. MOHAMMED, M.D.*; MOHAMAD M. MOTAWEA, M.D.** and FADY A. KYRILLOS, M.D.** \\ The Departments of Diagnostic Radiology* and Diabetes \& Endocrinology**, Faculty of Medicine, Mansoura University, Egypt
}

\begin{abstract}
Background: Foot ulcer is a serious complication of diabetes which can cause patient disability. High plantar pressure is one of the risk factors for ulcer formation. Pedal Soft Tissue (PST) thickness is essential in keeping its cushioning effect. Atrophy of PST leads to increase in the plantar pressure, which subsequently leads to ischemia and ulceration.

Aim of Study: To compare the PST thickness opposite the Metatarsal Heads (MTHs) in diabetic patients with and without peripheral neuropathy using Ultrasound (US) as an easy, available, and non-invasive tool.
\end{abstract}

Material and Methods: We examined the feet $(n=96)$ of 48 diabetic patients using high-frequency US imaging (10$13 \mathrm{MHz}$ ). We divided the patients into 2 groups. The first group included 24 diabetic patients with peripheral neuropathy (mean age $56 \pm 6$ years), and the second group included 24 diabetic patients without peripheral neuropathy (mean age $57 \pm 5$ years). We measured and compared the vertical thickness of PST superficial to flexor tendons opposite all MTHs in between the 2 groups using independent-sample- $t$-test.

Results: There was statistically significant difference in mean PST thickness under all left MTHs (first 5 vs. 6.4; second 6.1 vs. 7.8 ; third 6.2 vs. 7.4 ; fourth 5.6 vs. 6.9 ; fifth 4 vs. $5.7 \mathrm{~mm} ; p<0.05)$, and the first, second, third and fifth right MTHs (first 5.1 vs. 6.3 ; second 6.1 vs. 7.5 ; third 5.8 vs. 7.3; fifth 4.4 vs. $5.9 \mathrm{~mm} ; p<0.05$ ) between the first and second groups, respectively. Age, Body Mass Index (BMI) and sex had no significant effect on PST thickness in both groups.

Conclusion: Our study confirmed that US is effective, easy, available, harmless, low cost, non-invasive imaging tool that detects more PST atrophy in diabetic patients with peripheral neuropathy than that occurs in diabetic patients without peripheral neuropathy.

Key Words: Ultrasound-Diabetes - Pedal soft tissue thickness - Neuropathy.

Correspondence to: Dr. Nehal T. Mohammed, E-Mail: nehaltharwat83@gmail.com

\section{Introduction}

DIABETES is considered a widespread public health problem. According to the International Diabetes Federation estimation, there were 451 million diabetic patients (age range 18-99 years) worldwide in 2017 [1,2]. Diabetic Peripheral Neuropathy (DPN) is the commonest cause of neuropathy all over the world. About half of diabetic patients are estimated to have DPN, and about $10 \%-20 \%$ have severe symptoms that warrant treatment [3-6].

Understanding and early controlling the risk factors for neuropathy development is essential for successful treatment of diabetes and preventing DPN-related serious complications (ulcer, gangrene, and amputation) as well as social disease burden [7-10]. There is no specific treatment for DPN at present, therefore early prediction of its complications is of great significance. According to previous literature, ulcers can be reduced by $60 \%$ and amputations by about $85 \%$ with appropriate interventions in high risk diabetic neuropathy patients [1114].

High plantar pressure is one of the risk factors for foot ulcer formation which is a disabling consequence of diabetes [15]. Pedal Soft Tissue (PST) thickness plays an important role in reduction of the plantar pressure by its cushioning effect, its atrophy results in high plantar pressure that causes ischemia with subsequent ulceration [16]. Aging

\footnotetext{
Abbreviations:

PST : Pedal Soft Tissue.

MTHs : Metatarsal Heads.

US : Ultrasound.

BMI : Body Mass Index.

DPN : Diabetic Peripheral Neuropathy.
} 
process and diabetes are the most common causes of PST atrophy in patients with diabetic foot ulceration. Several studies have demonstrated the decrease in PST thickness among diabetic patients by using pedobarography and F-scan mat systems [17-20].

Many researchers tried to reach effective methods that can compensate the PST atrophy, such as fat grafting and silicone injection. However, up till now there are no standards defining PST atrophy or guidelines for the required PST thickness using supplementation that can treat or prevent the development of diabetic foot ulcers [17]

Ultrasound (US) has many advantages. US is widely available, quick, of low cost, lack ionizing radiation, better tolerated by the patient and can be performed when there is contraindication to Magnetic Resonance Imaging (MRI) in patients with metallic devices. In addition, US can be used to guide therapeutic interventions. Foot US is usually performed with a $13-17 \mathrm{MHz}$ linear array transducer. The major barrier for the use of US in assessment of the foot is due to limited experience with this technique and its normal anatomic sonographic appearance [21,22]

On the other hand, MRI is not easily available and of high cost despite its good soft tissue characterization. There are also limitations of MRI examination in patients with claustrophobia, metallic device, un co-operative patients in addition to long examination time [21,22]

In the current study, high-frequency US imaging was used to measure the difference of PST thickness below the Metatarsal Heads (MTHs) between diabetic patients with and without peripheral neuropathy.

\section{Patients and Methods}

Approval of institutional board for the study and written informed consent from all participants were obtained. Our study was a prospective study conducted at Radiology Department-Mansoura University Hospitals. In the period from September 2019 to March 2020, we assessed 48 diabetic patients (96 feet) referred from diabetic outpatient clinic, they were subdivided into 2 groups. Group I included 24 patients with DPN, and group II included 24 patients without peripheral neuropathy. Neuropathy was diagnosed on the basis of Vibration Perception Threshold (VPT) $>25$ volts on the tip of the hallux of both feet, using a neurothesiometer and loss of protective sensation on 10 grams monofilament test.

\section{Inclusion criteria:}

Patients aged $>40$ years, with ankle brachial index $>0.9$ were included in this study.

\section{Exclusion criteria:}

All diseases and variables other than diabetes which could affect PST thickness were excluded from the study. So, we excluded patients having osteomyelitis, soft tissue swelling and infections, callus formation, foot deformity, rheumatoid arthritis, peripheral arterial disease and those with previous diabetic foot ulcers.

\section{Measurement of pedal soft tissue thickness:}

All patients' feet were examined with high frequency US linear probe $(10-13 \mathrm{MHz})$ using Logic P5 GE device (made in China). The patient lie supine with the plantar aspect of the foot facing examiner. The probe is placed longitudinally over the MTH which is known by its rounded echogenic cortex. The overlying flexor tendon is identified by its fibrillar echotexture. For accurate tendon delineation, the US beam should be perpendicular to its fibers with the probe positioned along the long axis of its fibers. Normal tendons appear as compact linear bands of echogenic tissue which contains fine mixed internal hyperechoic and hypoechoic fibrillar echotexture. Then the vertical thickness of PST superficial to the tendons is measured opposite each MTH.

\section{Statistical analysis:}

Data were analyzed by IBM SPSS Statistics for Windows, Version 22.0. IBM Corp. Released 2013. Armonk, NY: IBM Corp. Qualitative data were expressed as count and percent. Quantitative data were tested for normality using Shapiro-Wilk's test with data being normally distributed if $p>0.050$. Quantitative data were expressed as mean \pm Standard Deviation (SD) if normally distributed or median and Interquartile Range (IQR) if not. We used Fisher's exact test for comparison of qualitative data. We used independent Samples $t$-test for comparison of quantitative data between two groups when data were normally distributed in both groups. The non-parametric alternative Mann-Whitney Utest was used if not. To determine the strength and direction of a linear relationship between two variables, we used Pearson's correlation (continuous normally distributed) and Spearman's correlation (continuous non-normally distributed or ordinal). For these tests, $p$-value is considered statistically significant when $\leq 0.05$. 


\section{Results}

Forty-eight diabetic patients (96 feet) were included in this study and were classified into 2 groups. Group I included 24 diabetic patients with DPN (12 males [50\%] and 12 females [50\%]) and group II included 24 diabetic patients without peripheral neuropathy (10 males [42\%] and 14 females [58\%]). For group I, the mean age was $56 \pm 6$ years, and for group II was $57 \pm 5$ years ( $p=$ $0.74)$. The average Body Mass Index (BMI) for group I was $36.1 \pm 7 \mathrm{~kg} / \mathrm{m}^{2}$, and for group II was $36.4 \pm 8.4 \mathrm{~kg} / \mathrm{m}^{2}(p=0.9)$. There was no statistically significant difference as regard these parameters between the 2 groups. All the patients had type 2 diabetes with average disease duration $16 \pm 6$ years for group I and $6.6 \pm 8.5$ years for group II ( $p=$ $0.003)$.

We compared the PST thickness under all MTHs between the 2 groups using independent- sample$t$-test. There was statistically significant difference in mean PST thickness under all left MTHs (first
5 vs. 6.4 ; second 6.1 vs. 7.8 ; third 6.2 vs. 7.4 ; fourth 5.6 vs. 6.9 ; fifth 4 vs. $5.7 \mathrm{~mm} ; p<0.05$ ), and the first, second, third and fifth right MTHs (first 5.1 vs. 6.3 ; second 6.1 vs. 7.5 ; third 5.8 vs. 7.3 ; fifth 4.4 vs. $5.9 \mathrm{~mm} ; p<0.05$ ) between the first and second groups respectively (Table 1), Figs. $(1,2)$. To determine the relationship between the PST thickness and age, we used Pearson's correlation which shows no significant correlation in-between at all MTHs of the right and left feet $(p>0.05)$ except at left $3 \mathrm{rd}$ and 4 th MTHs ( $p=0.02,0.04$ respectively). Pearson's correlation also shows no relationship between BMI or gender and PST thickness $(p>0.05)$. Finally, Spearman's correlation shows no relationship between duration of diabetes and PST thickness $(p>0.05)$.

Receiver Operating Characteristic (ROC) curve analysis showed that PST thickness at all MTHs except right 4 th $\mathrm{MTH}$ is a good discriminator between diabetic patients with and without DPN Fig. (3).

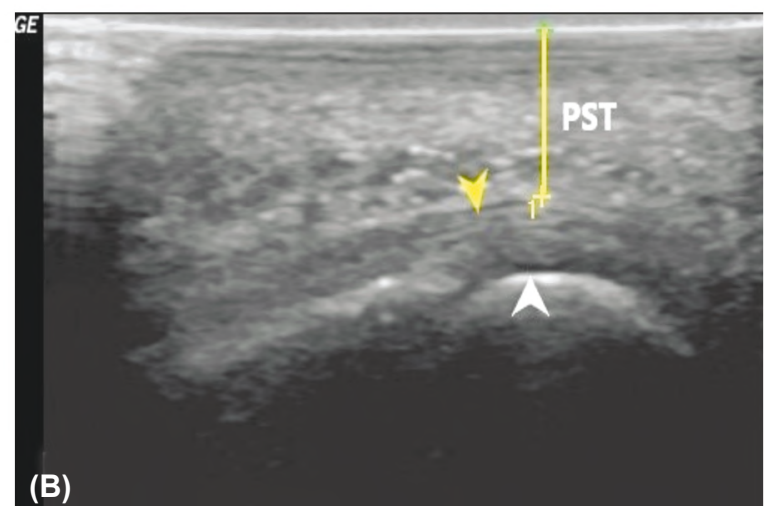

Fig. (1): Superficial US examination of Pedal Soft Tissue (PST) in longitudinal plane showing pedal soft tissue thickness (yellow line) superficial to flexor tendon (T: Yellow arrowhead) opposite right 1 st Metatarsal Head (MTH) its cortex is identified as curved echogenic line (white arrowhead) in 2 diabetic patients A) With peripheral neuropathy measuring 5.9mm and B) Without peripheral neuropathy measuring $7.2 \mathrm{~mm}$, denoting that greater pedal soft tissue atrophy occurs in diabetic patients with peripheral neuropathy.
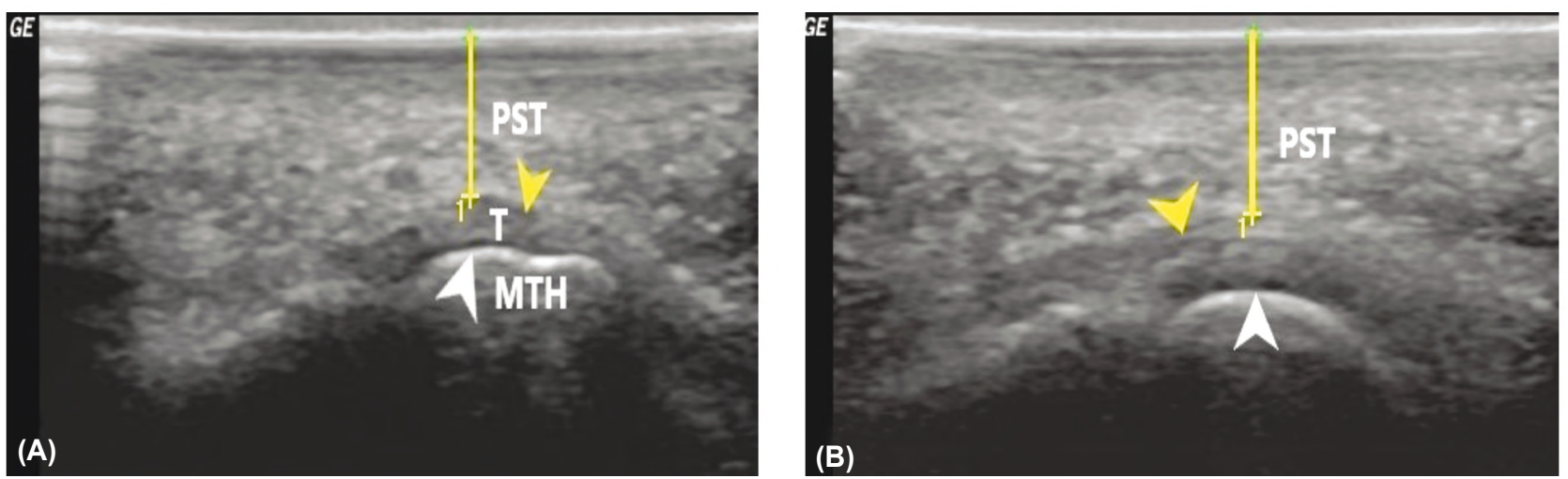

Fig. (2): Superficial US examination of Pedal Soft Tissue (PST) in longitudinal plane showing pedal soft tissue thickness (yellow line) superficial to flexor tendon (T: Yellow arrowhead) opposite left 1 st metatarsal head (white arrowhead) in 2 diabetic patients A) With peripheral neuropathy measuring $5.6 \mathrm{~mm}$ and B) Without peripheral neuropathy measuring $6.8 \mathrm{~mm}$. 


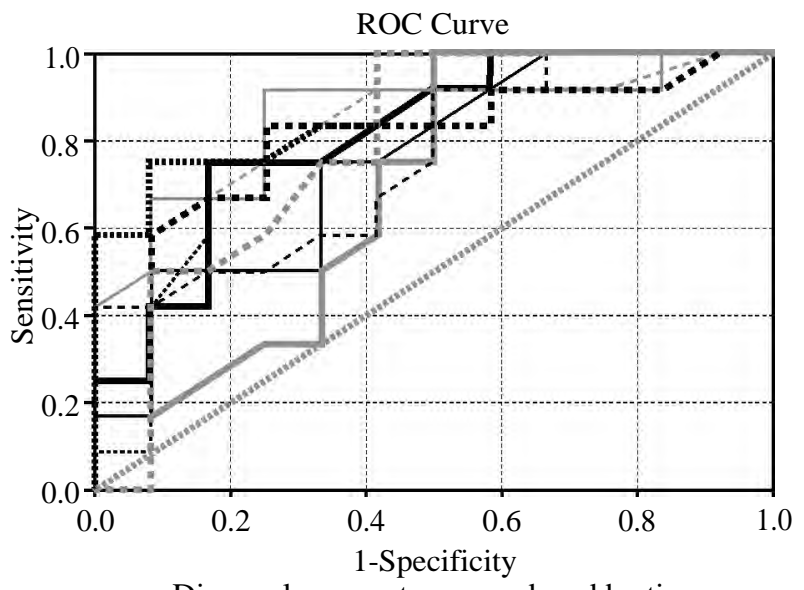

Diagonal segments are produced by ties

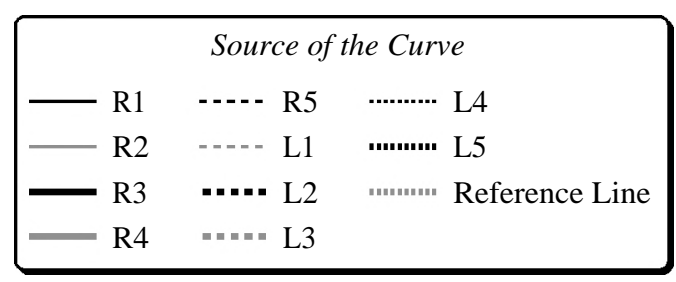

Fig. (3): Area under the ROC curve for pedal soft tissue thickness under the metatarsal heads.

Table (1): Differences in pedal soft tissue thickness under the metatarsal heads between the two groups.

\begin{tabular}{lccc}
\hline & \multicolumn{2}{c}{ Pedal soft tissue thickness (mm) } & \\
\cline { 2 - 3 } $\begin{array}{l}\text { Metatarsal } \\
\text { head }\end{array}$ & $\begin{array}{c}\text { Group I } \\
\text { (with peripheral } \\
\text { neuropathy) }\end{array}$ & $\begin{array}{c}\text { Group II } \\
\text { (no peripheral } \\
\text { neuropathy) }\end{array}$ & $\begin{array}{c}p \text { value* } \\
\text { neunn}\end{array}$ \\
\hline R1 & $5.1 \pm 0.9$ & $6.3 \pm 1.4$ & .02 \\
R2 & $6.1 \pm 1$ & $7.5 \pm 1.1$ & .004 \\
R3 & $5.8 \pm 1.2$ & $7.3 \pm 1.2$ & .009 \\
R4 & $6 \pm 1$ & $6.9 \pm 1.6$ & .11 \\
R5 & $4.4 \pm 1.2$ & $5.9 \pm 1.7$ & .02 \\
L1 & $5 \pm 1.1$ & $6.4 \pm 0.9$ & .002 \\
L2 & $6.1 \pm 1$ & $7.8 \pm 0.9$ & .004 \\
L3 & $6.2 \pm 0.9$ & $7.4 \pm 1$ & .03 \\
L4 & $5.6 \pm 1.2$ & $6.9 \pm 1.1$ & .009 \\
L5 & $4 \pm 1.1$ & $5.7 \pm 0.8$ & .001 \\
\hline R1: Right 1st metatarsal head. & L2: Left 2nd metatarsal head. \\
R2: Right 2nd metatarsal head. & L3: Left 3rd metatarsal head. \\
R3: Right 3rd metatarsal head. & L4: Left 4th metatarsal head. \\
R4: Right 4th metatarsal head. & L5: Left 5th metatarsal head. \\
R5: Right 5th metatarsal head. & Data presented as mean \pm SD. \\
L1: Left 1st metatarsal head. & *: Independent 2-sample $t$-test. \\
\end{tabular}

\section{Discussion}

The foot plays an important role in standing and movement as well as supporting the body weight and keeping its balance. Difficulty in walking or standing has adverse effect on the quality of life. Cases with diabetic foot ulceration may require amputation with subsequent loss of the foot function. Also, wounds in diabetic patients are difficult to heal with progression to infection and necrosis of the soft tissue with serious complications. Thus, management and protection against diabetic foot ulcers are very important to maintain the patients' good quality of life [15]

Management and prevention of diabetic foot ulcers include external support and internal support. External support is done by using foot pads, total contact casts, and customized shoes. Internal support includes surgical intervention, such as filler injection, silicone injection, decompression, and soft tissue grafting [23-25]. Methods of external support could provide variable results depending on the patient compliance. Despite their invasive nature, methods of internal support may provide more favorable results especially fat or filler injection. However, due to lack of information about the normal soft tissue thickness in diabetic patients and healthy individuals, there are no available standards about the amount of fat or filler that should be injected with subsequent difficult decision for the use of such techniques [26].

US examination with high resolution linear array probe has increasingly become important in assessment of soft tissue, ligaments and tendons of the foot being of low cost, widely available, fast and lack ionizing radiation. In addition, it allows performance of dynamic examination and guide therapeutic interventions. However, its main limitation is that it is operator dependent. Several studies found comparable high accuracy and sensitivity between US and MRI in assessment of soft tissue, tendons and ligaments of the foot. US is excellent for imaging soft tissue abnormalities and used as primary tool of investigation [27] .

In this study, we used US to compare the thickness of PST between diabetic patients with and without peripheral neuropathy. We found that there was statistically significant difference in PST thickness under all left MTHs, and the first, second, third and fifth right MTHs between the first and second groups respectively. After review of literature, there was lack of researches assessing and comparing PST thickness. Our study comes in agreement with the study done by Oh et al., (2018) which compared the PST thickness between diabetic patients and non-diabetic subjects using MRI scanner, and found that atrophy of PST occurred in diabetic group [28]. Also, our study is supported by Perry et al., (1995) who evaluated the plantar pressure in different foot regions during walking using platform pedobarography, and they found that the area under the MTHs experienced higher plantar pressure than other regions, in addition to being thinner in diabetic patients compared to non- 
diabetics [29]. In their study, Abouaesha et al., (2001) measured plantar foot pressure and PST thickness opposite each MTH in 157 patients with diabetic neuropathy by using optical pedobarograph and US scanning platform, and they found a significant inverse correlation between dynamic plantar pressure and plantar soft tissue thickness. This finding led them to think about supplementation techniques, such as fat grafts or silicone injection below the MTHs with soft tissue atrophy that can lead to good results as regard management and protection against diabetic foot ulcers [30].

Another study by Gusenoff et al., (2016) found that supplementation techniques results in reduction of the plantar pressure and improvement of the pain. However, the amount of supplementation cannot be accurately detected due to the lack of standard definition of soft tissue atrophy. Therefore, they used to use fat in amount sufficient to protect against development of tenderness or skin blanching in the donor site. The difference in soft tissue thickness between diabetics with and without peripheral neuropathy and between diabetic and nondiabetic subjects might provide foot careers with more accurate standard information for using different PST supplementation techniques [31].

We expected that age related soft tissue atrophy could also occur in the feet. However, no statistically significant difference in the PST thickness was noted in this study among the patients with different age groups, likely attributed to the small number of patients in each group. However, our results come in agreement with Oh et al., (2018) who also found no statistically significant difference in the PST thickness in patients with different age groups [28]

Also, we found no significant relationship between BMI or gender and PST thickness. Finally, there was no significant relationship between duration of diabetes and PST thickness.

The limitation of the present study was the small sample size of each group. Further studies with large-scale trials on a large number of nondiabetic and diabetic patients with and without peripheral neuropathy should be conducted.

\section{Conclusion:}

We concluded that US is a good imaging tool for assessment of PST thickness and we found that greater atrophy of PST under the MTHs occurs in diabetic patients with peripheral neuropathy than those without peripheral neuropathy. A study on a large scale is needed to detect the quantitative difference in PST thickness among diabetic patients with and without peripheral neuropathy, which can help in standardization of definition of PST atrophy with subsequent standardization of the amount of fat graft or silicone injection needed for protection against and management of diabetic foot ulcers.

\section{References}

1- LIU X., XU Y., AN M. and ZENG Q.: The risk factors for diabetic peripheral neuropathy: A meta-analysis. PLoS ONE, 14: e0212574, 2019.

2- CHO N.H., SHAW J.E., KARURANGA S., HUANG Y., Da ROCHA FERNANDES J.D., OHLROGGE A.W., et al.: IDF Diabetes Atlas: Global estimates of diabetes prevalence for 2017 and projections for 2045. Diabetes Res. Clin. Pract., 138: 271-81, 2018

3- HICKS C.W. and SELVIN E.: Epidemiology of peripheral neuropathy and lower extremity disease in diabetes. Curr. Diab. Rep., 19: 86-98, 2019.

4- ARGOFF C.E., COLE B.E., FISHBAIN D.A. and IRVING G.A.: Diabetic peripheral neuropathic pain: Clinical and quality of life issues. Mayo Clin. Proc., 81: S3-11, 2006

5- IQBAL Z., AZMI S., YADAV R., FERDOUSI M., KUMAR M., CUTHBERTSON D.J., et al.: Diabetic peripheral neuropathy: Epidemiology, diagnosis, and pharmacotherapy. Clin. ther., 40: 828-49, 2018.

6- ANDERSEN S.T., WITTE D.R., DALSGAARD E.M., ANDERSEN H., NAWROTH P., FLEMING T., et al.: Risk factors for incident diabetic polyneuropathy in a cohort with screen-detected type 2 diabetes followed for 13 years: ADDITION-Denmark. Diabetes Care, 41: 1068$75,2018$.

7- CALLAGHAN B.C., GAO L., LI Y., ZHOU X., REYNOLDS E., BANERJEE M., et al.: Diabetes and obesity are the main metabolic drivers of peripheral neuropathy. Ann. Clin. Transl. Neurol., 5: 397-405, 2018.

8- POP-BUSUI R., BOULTON A.J., FELDMAN E.L., BRIL V., FREEMAN R., MALIK R.A., et al.: Diabetic neuropathy: A position statement by the American Diabetes Association. Diabetes Care, 40: 136-54, 2017.

9- CALLAGHAN B.C., CHENG H.T., STABLES C.L., SMITH A.L. and FELDMAN E.L.: Diabetic neuropathy: Clinical manifestations and current treatments. Lancet Neurol., 11: 521-34, 2012.

10- YANG H., SLOAN G., YE Y., WANG S., DUAN B., TESFAYE S., et al.: New perspective in diabetic neuropathy: From the periphery to the brain, a call for early detection, and precision medicine. Front Endocrinol., 10: 929-41, 2020.

11-WON J.C. and PARK T.S.: Recent advances in diagnostic strategies for diabetic peripheral neuropathy. Endocrinol metab., 31: 230-8, 2016

12- NING G.: Progress in the diagnosis of diabetic peripheral neuropathy. Chinese Journal of Practical Internal Medicine, 7: 487-9, 2007.

13- GORE M., BRANDENBURG N.A., DUKES E., HOFFMAN D.L., TAI K.S. and STACEY B.: Pain severity in diabetic peripheral neuropathy is associated with patient functioning, symptom levels of anxiety and depression, 
and sleep. Journal of pain and symptom management, 30: 374-85, 2005.

14- TESFAYE S., SELVARAJAH D., GANDHI R., GREIG M., SHILLO P., FANG F., et al.: Diabetic peripheral neuropathy may not be as its name suggests: Evidence from magnetic resonance imaging. Pain, 157: S72-80, 2016.

15- SEO D.K. and LEE H.S.: Management of diabetic foot ulcer. J. Korean Foot Ankle Soc., 18: 1-7, 2014.

16- MICKLE K.J.: Soft tissue thickness under the metatarsal heads is reduced in older people with toe deformities. J. Orthop. Res., 29: 1042-6, 2011.

17- VAN SCHIE C.H., WHALLEY A., VILEIKYTE L., WIGNALL T., HOLLIS S. and BOULTON A.J.: E-cacy of injected liquid silicone in the diabetic foot to reduce risk factors for ulceration: A randomized double-blind placebo-controlled trial. Diabetes Care, 23: 634-8, 2000.

18- ABOUAESHA F., VAN SCHIE C.H., ARMSTRONG D.G. and BOULTON A.J.: Plantar soft-tissue thickness predicts high peak plantar pressure in the diabetic foot. J. Am. Podiatr. Med. Assoc., 94: 39-42, 2004.

19- FAWZY O.A., ARAFA A.I., EL WAKEEL M.A. and ABDUL KAREEM S.H.: Plantar pressure as a risk assessment tool for diabetic foot ulceration in Egyptian patients with diabetes. Clin. Med. Insights Endocrinol. Diabetes, 7: 31-9, 2014.

20- PARK Y.K., LEE J.Y., JUNG S. and RYU K.H.: The relationship between body mass index and diabetic foot ulcer, sensory, blood circulation of foot on type II diabetes mellitus patients. J. Korean Orthop. Assoc., 53: 136-42, 2018.

21- DONOVAN A., ROSENBERG Z.S., BENCARDINO J.T., VELEZ Z.R., BLONDER D.B., CIAVARRA G.A., et al.: Plantar tendons of the foot: MR imaging and US. Radiographic, 33: 2065-85, 2013.

22- DRAGHI F., GITTO S., BORTOLOTTO C., DRAGHI A.G. and BELOMETTI G.O.: Imaging of plantar fascia disorders: Findings on plain radiography, ultrasound and magnetic resonance imaging. Insights Imaging, 8: 69-78, 2017.
23- BOULTON A.J.: Pressure and the diabetic foot: Clinical science and offloading techniques. Am. J. Surg., 187: 17S-24S, 2004.

24- BUS S.A., VALK G.D., VAN DEURSEN R.W., ARMSTRONG D.G., CARAVAGGI C., HLAVACEK P., et al.: The effectiveness of footwear and offloading interventions to prevent and heal foot ulcers and reduce plantar pressure in diabetes: A systematic review. Diabetes Metab. Res. Rev., 24: S162-S180, 2008.

25- KIM J.B., LEE B.J., KIM C.U. and JUNG D.: Treatment using a single-lobed rotation flap in diabetic forefoot ulceration: Five case reports. J. Korean Foot Ankle Soc., 23: 208-11, 2019.

26- VAN SCHIE C.H., WHALLEY A., ARMSTRONG D.G., VILEIKYTE L. and BOULTON A.J.: The effect of silicone injections in the diabetic foot on peak plantar pressure and plantar tissue thickness: A 2-year follow-up. Arch. Phys. Med. Rehabil., 83: 919-23, 2002.

27- EL-LIETHY N. and KAMAL H.: High resolution ultrasonography and magnetic resonance imaging in the evaluation of tendino-ligamentous injuries around ankle joint. EJRNM, 47: 543-55, 2016.

28- OH S., KIM J., CHOI J., JEONG W., CHANG H. and LEE S.: Comparison of pedal soft tissue thickness between those with and without diabetes. J. Foot Ankle Surg., 57: 860-4, 2018.

29- PERRY J.E., ULBRECHT J.S., DERR J.A. and CAVANAGH P.R.: The use of running shoes to reduce plantar pressures in patients who have diabetes. J. Bone Joint Surg. Am., 77: 1819-28, 1995.

30- ABOUAESHA F., VAN SCHIE C.H., GRIFFTHS G.D., YOUNG R.J. and BOULTON A.J.: Plantar tissue thickness is related to peak plantar pressure in the high-risk diabetic foot. Diabetes Care, 24: 1270-4, 2001.

31- GUSENOFF J.A., MITCHELL R.T., JEONG K., WUKICH D.K. and GUSENOFF B.R.: Autologous fat grafting for pedal fat pad atrophy: A prospective randomized clinical trial. Plast. Reconstr. Surg., 138: 1099-108, 2016. 


\section{إستخدام الموجات الصوتية فى تقييم سماكة آنسجة باطن القدم الرخوه

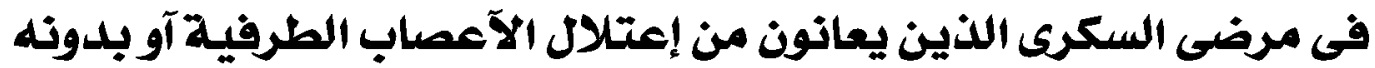

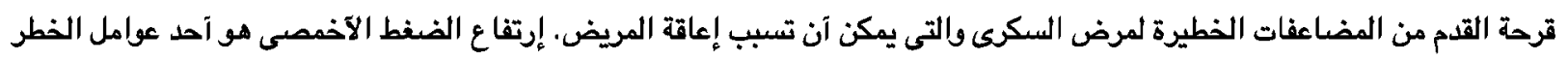

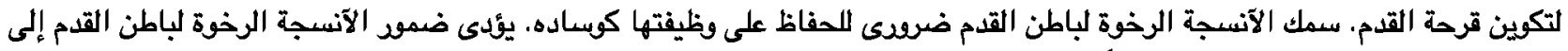

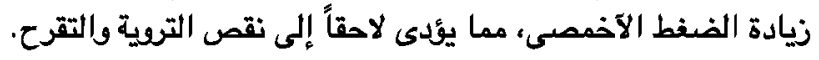

الفرض من الدراسة: مقارنة سمك آنسجة باطن القدم الرخوه مقابل رئوس عظام المشط فى مرضى السكرى الذين يعانون من الإعتلال العصبى الطرفى آو بدونه بإستخدام الموجات الصوتية.

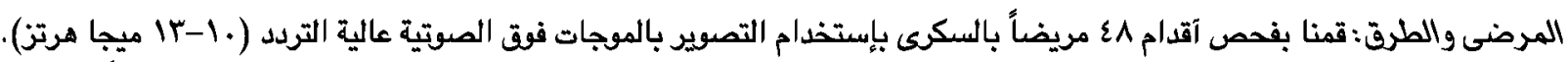

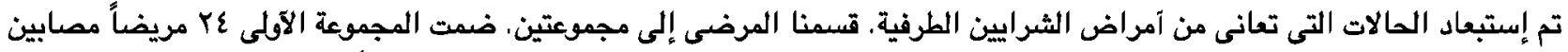

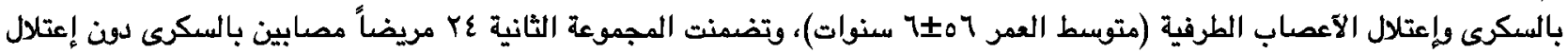

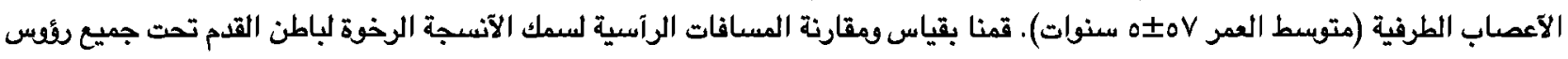
عظام المشط بين المجموعتين.

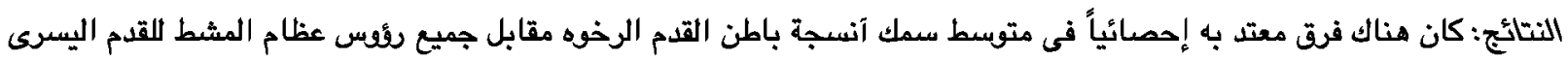

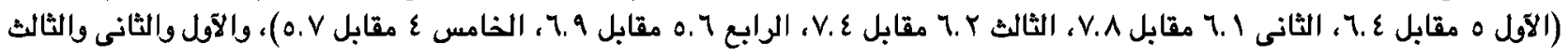

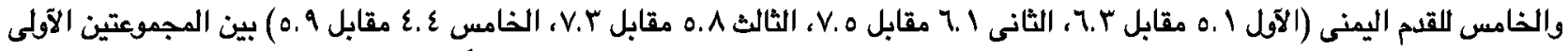

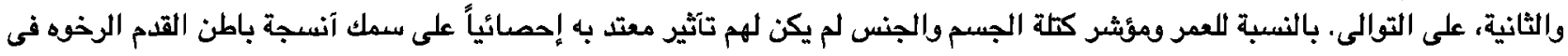
كتا المجموعتين.

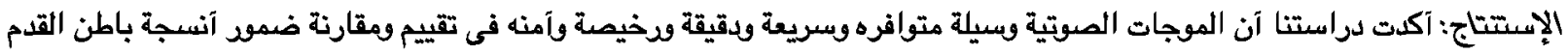

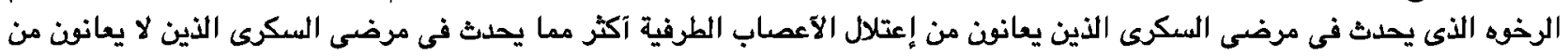

